\title{
Role of pulmonary hemodynamics in determining 6-minute walk test result in atrial septal defect: an observational study
}

\author{
Supomo Supomo ${ }^{1 *}$ D, Handy Darmawan² and Adika Zhulhi Arjana ${ }^{2}$
}

\begin{abstract}
Background: The presence of altered pulmonary hemodynamics in adult patients with atrial septal defect (ASD) is common. However, there are no observational studies which evaluate the impact of altered pulmonary hemodynamics on the 6-min walk test (6MWT) result. This study aimed to investigate the role of pulmonary hemodynamics in determining $6 \mathrm{MWT}$ result of patients with ASD.

Method: Forty-six consecutive adult patients with ASD were included in this study. Right heart catheterization was performed to obtain the pulmonary hemodynamics profile. Meanwhile, 6MWT was presented as high or low with cut-off point $350 \mathrm{~m}$. Receiver operating characteristic (ROC) was used for analytical methods.

Result: Abnormal functional capacity was indicated by ROC result of mPAP cut-off value of $>24 \mathrm{mmHg}(p=0.0243$; $A U C=0.681)$. The value of PVR $>3.42$ woods unit $(W U)$ showed high specificity in determining abnormal functional capacity $(p=0.0069$; AUC $=0.713)$. Flow ratio with cut-off point $\leq 4.89$ had the highest sensitivity $(100 \%)(p=0.8300$; AUC $=0.520$ ).

Conclusion: Pulmonary hemodynamics can serve as an indicator of 6MWT result in adult ASD patients with values of $\mathrm{mPAP}>24 \mathrm{mmHg}$ and PVR $>3.42 \mathrm{WU}$.
\end{abstract}

Keywords: Atrial septal defect, Cardiac catheterization, Hemodynamic, Pulmonary hypertension

\section{Background}

Atrial septal defect (ASD) is a common congenital heart disease (CHD) with 1.64 per 1000 living birth prevalence and female predominance [1]. Ninety percent of the patients were reported to survive into adulthood and $35 \%$ of them developed secondary pulmonary hypertension $(\mathrm{PH})[2,3]$, which is defined as increased mean pulmonary artery pressure $(\mathrm{mPAP}) \geq 25 \mathrm{mmHg}$ in right heart catheterization (RHC) [4].

The presence of altered pulmonary hemodynamics due to secondary PH in adult patients with ASD is associated with reduced survival and high hospital utilization $[5,6]$. Previous studies had presented the impact of altered pulmonary hemodynamics due to primary $\mathrm{PH}$ to functional capacity of the patient, which was measured by the 6-

\footnotetext{
* Correspondence: supomo.tkv@mail.ugm.ac.id

${ }^{1}$ Department of Thoracic and Cardiovascular Surgery, Dr. Sardjito General Hospital, Faculty of Medicine, Public Health and Nursing, Universitas Gadjah Mada, Kesehatan St. Number 1, Sleman, Yogyakarta 55281, Indonesia Full list of author information is available at the end of the article
}

min walk test $(6 \mathrm{MWT})[7,8]$. The $6 \mathrm{MWT}$ result represents the functional capacity and predicts the outcome of the patient with $\mathrm{PH}$. Values of 6MWT distance less than $350 \mathrm{~m}$ are a predictor of worse outcome [9].

In our knowledge, there has not been any observational studies which evaluate the impact of altered pulmonary hemodynamics due to secondary $\mathrm{PH}$ on adult patients with ASD on the 6MWT result. We conducted this study to investigate the role of each of the components of pulmonary hemodynamics in determining the 6MWT result.

\section{Methods}

Study participants and ethical consideration

Between January 2014 and March 2017, 46 consecutive patients with ASD in Dr. Sardjito General Hospital were included in this study. The inclusion criteria were: adults above 18 years of age, who were diagnosed with ASD. The diagnosis of ASD was confirmed by either transthoracic echocardiography or transesophageal echocardiography. 
This study included subjects who had not underwent ASD closure or vasodilator therapy to decrease PAP. This study was approved by the Institutional Ethics Committee of Faculty of Medicine, Public Health and Nursing of Universitas Gadjah Mada, Indonesia and the need for individual informed consent was waived.

\section{Study protocols and definitions}

All of the subjects underwent RHC to obtain their pulmonary hemodynamic profile. Pulmonary hemodynamic profile components analyzed in this study were mPAP, pulmonary vascular resistance (PVR), and flow ratio. Flow ratio is defined as ratio of Qp and Qs taken from RHC data.

$$
Q_{p}=\frac{\mathrm{O}_{2} \text { consumption }(\mathrm{mL} / \mathrm{min})}{\mathrm{PV} \mathrm{O}_{2} \text { content }(\mathrm{mL} / \mathrm{L})-\mathrm{PA} \mathrm{O}_{2} \text { content }(\mathrm{mL} / \mathrm{L})}
$$

$$
\mathrm{Q}_{\mathrm{s}}=\frac{\mathrm{O}_{2} \text { consumption }(\mathrm{mL} / \mathrm{min})}{\mathrm{SA} \mathrm{O}_{2} \text { content }(\mathrm{mL} / \mathrm{L})-\mathrm{PA} \mathrm{O}_{2} \text { content }(\mathrm{mL} / \mathrm{L})}
$$

PV (pulmonary vein); PA (pulmonary artery); SAO2 (blood oxygen saturation); MVO2 (myocardial volume oxygen).

High flow ratio is defined as Qp/Qs $>2.36$ [10]. The $\mathrm{PH}$ was diagnosed when mPAP was $\geq 25 \mathrm{mmHg}$ in RHC. The $6 \mathrm{MWT}$ was performed after RHC to obtain the information regarding the functional capacity of the patients according to American Thoracic Society guidelines [11]. It was performed indoors on a long, flat, straight, and hard surface. This test measures the distance in meters which a patient can quickly reach unassisted in $6 \mathrm{~min}$. The abnormal functional capacity was defined as 6MWT distance less than $350 \mathrm{~m}$. All patients were not provided supplemental oxygen while

\begin{tabular}{|c|c|c|c|}
\hline Variables & N (\%) & Mean \pm SD & Median (min-max) \\
\hline $\mathrm{PH}$ & $25(54.3)$ & & \\
\hline Non-PH & $21(45.7)$ & & \\
\hline Systolic Pressure (mmHg) & & & $110(84-150)$ \\
\hline Diastolic Pressure (mmHg) & & & $70(60-104)$ \\
\hline Age (years) ${ }^{a}$ & & & $33(18-58)$ \\
\hline mPAP $(\mathrm{mmHg})$ & & $28.91 \pm 11.41$ & \\
\hline PVR $(W U)^{a}$ & & & $1.90(0.20-16.90)$ \\
\hline Flow Ratio $^{a}$ & & & $2.93(1.27-9.00)$ \\
\hline $6 \mathrm{MWT}(\mathrm{m})^{\mathrm{a}}$ & & & $366(119-800)$ \\
\hline Oxygen Saturation (\%) & & & $98(88-99)$ \\
\hline Normal 6MWT & $20(43.5)$ & & \\
\hline Abnormal 6MWT & $26(56.5)$ & & \\
\hline
\end{tabular}

Table 1 Baseline characteristic of the patients

${ }^{\mathrm{a}}$ Non-parametric data
Table 2 Difference characteristic between $\mathrm{PH}$ and non-PH

\begin{tabular}{llll}
\hline Variables & $\mathrm{PH}$ & Non-PH & $p$ \\
\hline ASD diameter $(\mathrm{mm})$ & $2.84 \pm 0.82$ & $2.47 \pm 0.78$ & 0.1154 \\
LA dimension $(\mathrm{mm})$ & $34.52 \pm 5.3$ & $31.86 \pm 5.03$ & 0.0727 \\
RA dimension $(\mathrm{mm})^{\mathrm{a}}$ & $48(38-69)$ & $45(30-50)$ & 0.0081 \\
LV dimension $(\mathrm{mm}) 37.45 \pm 5.37$ & $34.55 \pm 4.91$ & 0.0495 \\
RV dimension (mm) & $46.3 \pm 7.8$ & $42.41 \pm 4.15$ & 0.0384 \\
mPAP $(\mathrm{mmHg})$ & $36.42 \pm 9.69$ & $19.42 \pm 4.19$ & $<0.0001$ \\
PVR $(\mathrm{WU})^{\mathrm{a}}$ & $3.05(0.99-16.90)$ & $1.05(0.20-3.42)$ & $<0.0001$ \\
Flow Ratio & $2.70(1.27-4.89)$ & $3.12(1.50-9.00)$ & 0.3157 \\
6MWT (m) & $326(200-462)$ & $391(119-800)$ & 0.0119 \\
High Flow & $332.67 \pm 73.76$ & $357.87 \pm 83.41$ & $0.2288^{\mathrm{b}}$ \\
Low Flow & $373.5(118.2-800)^{\mathrm{a}}$ & $357 \pm 25.06$ & \\
\hline
\end{tabular}

${ }^{\mathrm{a}}$ Non-parametric data; ${ }^{\mathrm{b}}$ Analyzed by Kruskal Wallis

undergoing the 6MWT. Echocardiography data was used as a baseline data for further ASD evaluation.

\section{Statistical analysis}

Baseline characteristics of the patients are shown in Table 1. Continuous variables were presented as mean \pm standard deviation $(\mathrm{SD})$ and categorical variable was presented as percentage. Continuous variables with non-parametric data were presented in median. On bivariate analysis, difference between $\mathrm{PH}$ and non- $\mathrm{PH}$ is presented on Table 2. The results are considered to be significant if $p<0.05$. The relationship between $\mathrm{PH}$ and functional capacity was analyzed using chi-square test (Table 3). In addition, correlations between each pulmonary hemodynamics component and 6MWT were analyzed using Spearman's rank correlation test due to their nonparametric data (Fig. 1). The ROC analysis was used for analyzing capability of mPAP, PVR, and flow ratio in determining functional capacity of the patient, which was presented as binary data of normal or abnormal (Fig. 2). Statistical review of the study was performed by a biomedical statistician. The data were analyzed using Medcalc software.

\section{Results}

Twenty-five (54.3\%) patients had $\mathrm{PH}$ with mean mPAP $28.91 \pm 11.41 \mathrm{mmHg}$ (Table 1). On bivariate analysis, there were significant differences of $6 \mathrm{MWT}$

Table 3 Relationship between PH and functional capacity of the patient

\begin{tabular}{llll}
\hline Variables & $\begin{array}{l}\text { Abnormal functional } \\
\text { capacity } \\
(6 \mathrm{MWT}<350 \mathrm{~m})\end{array}$ & $\begin{array}{l}\text { Normal functional } \\
\text { capacity } \\
(6 \mathrm{MWT} \geq 350 \mathrm{~m})\end{array}$ & $p$ \\
\hline $\mathrm{PH}$ & 15 & 10 & 0.0302 \\
Non-PH & 5 & 16 & \\
\hline
\end{tabular}



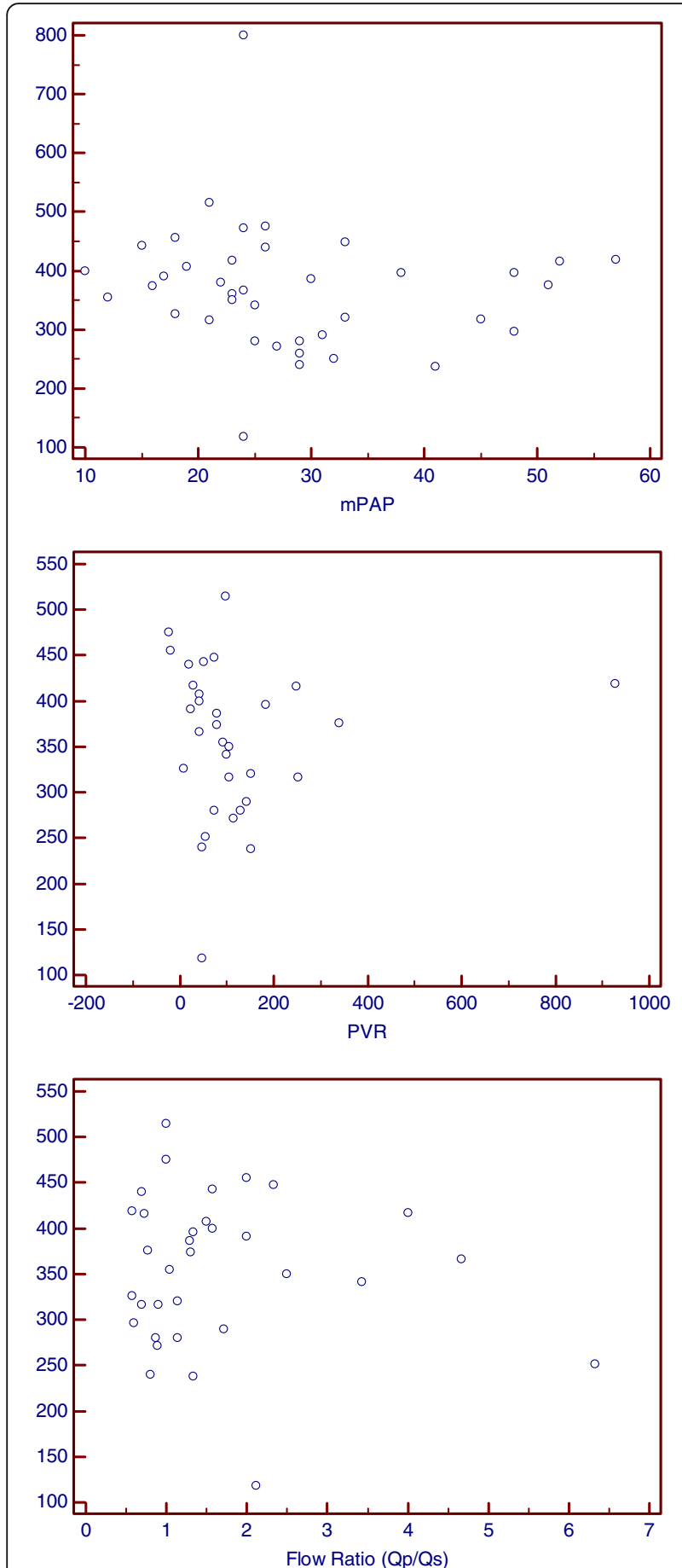

Fig. 1 mPAP, PVR, and Flow Ratio correlating to 6MWT plot analyzed with Spearman's rank correlation test $(r=-0.329 p=0.0238 ; r=-0.339$ $p=0.0212 ; r=-0.002 p=0.9850$ )

distance between $\mathrm{PH}$ and non-PH patients with $p=0$. 0119 (Table 2). Mann Whitney analysis on 6MWT for high flow ratio and low ratio group showed a significant result $(p=0.048)$. Kruskal Wallis analysis for all flow ratio group showed no significant result.
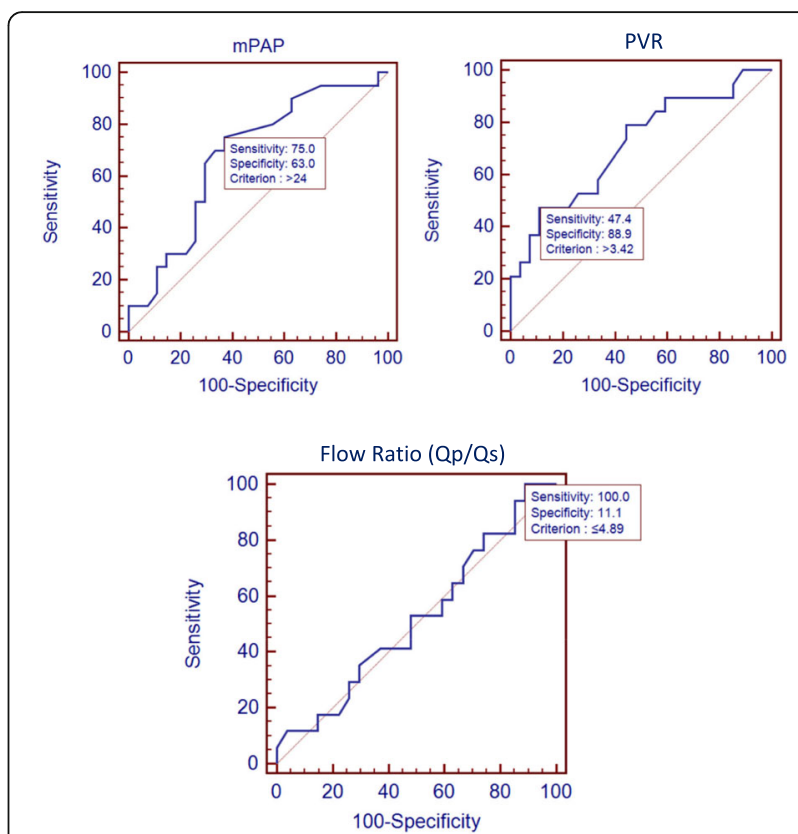

Fig. 2 Result of ROC analysis of mPAP, PVR, and Flow Ratio in determining abnormal functional capacity $(6 \mathrm{MWT}<350 \mathrm{~m})$

Relationship between $\mathrm{PH}$ and abnormal functional capacity of the patient was significant in chi-square analysis with $p=0.0302$ (Table 3). Figure 1 shows the correlations between pulmonary hemodynamics and $6 \mathrm{MWT}$ distance. Increased mPAP and pulmonary vascular resistance (PVR) were significantly correlated with decline in 6MWT distance $(p=0.0238$ and 0 . 0212, respectively). However, the correlation between increased flow ratio and declined 6MWT distance was not significant $(p=0.9850)$.

ROC analysis results are shown in Fig. 2. The mPAP cut-off value of $>24 \mathrm{mmHg}$ had $63 \%$ of specificity and $75 \%$ of sensitivity in determining abnormal functional capacity $(p=0.0243$; AUC $=0.681)$. The value of PVR > 3.42 woods unit (WU) was shown to have $88.9 \%$ of specificity and $47.4 \%$ of sensitivity in determining abnormal functional capacity $(p=0.0069$; AUC $=0.713)$. Flow ratio had the highest sensitivity (100\%) in determining abnormal functional capacity with cut-off point $\leq 4.89$. However, this result was not significant $(p=0.8300 ; \mathrm{AUC}=0$. $520)$ and had a very low specificity (11.11\%).

\section{Discussion}

In adult patients with ASD, the presence of $\mathrm{PH}$ was reported to have association with high mortality and hospital utilization $[5,6]$. The presence of $\mathrm{PH}$ itself is determined using the value of mPAP, which is one of the pulmonary hemodynamic components. The value of $\mathrm{mPAP} \geq 25 \mathrm{mmHg}$ is defined as $\mathrm{PH}$ [4]. However, whether this abnormal value also correlates with 
functional limitation of the patient or not has previously not been studied. This study strengthens the link between altered pulmonary hemodynamics and functional capacity in adult patients with ASD.

This study used 6MWT as an indicator of functional capacity. Earlier studies showed that $6 \mathrm{MWT}$ could substitute cardiopulmonary exercise testing to measure functional capacity in low resources setting [12-14]. Several studies demonstrated the impact of altered pulmonary hemodynamics on functional capacity of the patient, which was determined using 6MWT $[7,8]$. Minai et al. [7] found that patients with $\mathrm{PH}$ had significantly lower 6MWT compared to non-PH patients and mPAP was the best predictor of declined 6MWT distance in multivariate analysis. On the other hand, Miyamoto et al. [8] found that 6MWT significantly correlated with PVR, but was not significantly correlated with mPAP. These studies were conducted in patients with unexplained or primary $\mathrm{PH}$.

In the case of altered pulmonary hemodynamics in secondary $\mathrm{PH}$ due to ASD, our study showed significant difference in 6MWT distance between $\mathrm{PH}$ and non-PH patients (Table 2). After 6MWT distance was divided into normal and abnormal functional capacity, chisquare analysis also revealed a significant relationship between those variables (Table 3). Both increased mPAP and PVR were significantly correlated with declined 6MWT distance (Fig. 1). These results demonstrated that altered pulmonary hemodynamics have an impact on functional capacity of the adult patients with ASD.

Significant difference of 6MWT results between high and low flow ratio $\mathrm{PH}$ patients showed that functional capacity is correlated with shunt severity. Results from ROC analysis showed flow ratio of pulmonary to systemic circulation had the highest sensitivity (100\%) in determining abnormal functional capacity, but this result was not significant and had a very low specificity (11.1\%).

In addition, this study also analyzed the capability of each of the pulmonary hemodynamic components in determining abnormal functional capacity of the patients using ROC analysis. Significant result was shown by mPAP and PVR. The value of mPAP $>24 \mathrm{mmHg}$ (sensitivity $75 \%$, specificity $63 \%$ ) and PVR $>3.42 \mathrm{WU}$ (sensitivity $47.4 \%$, specificity $88.9 \%$ ) were determined to be predictors of this abnormal condition (Fig. 2).

\section{Limitations}

Our study has the limitation of using a cross-sectional design, which only provides the outcome and factors associated to it at a specific point of time. In addition, patients included in this study were only adult ASD patients with more than 18 years of age. Therefore, the results of this study may not be applicable for pediatric ASD patients.

\section{Conclusion}

The presence of altered pulmonary hemodynamic on secondary $\mathrm{PH}$ due to ASD in adult patients is associated with abnormal functional capacity. Values of mPAP> $24 \mathrm{mmHg}$ and PVR $>3.42 \mathrm{WU}$ were found to be indicators of this abnormal condition.

\section{Abbreviations \\ 6MWT: 6-min walk test; ASD: Atrial septal defect; CHD: Congenital heart disease; mPAP: Mean pulmonary artery pressure; $\mathrm{PH}$ : Pulmonary hypertension; PVR: Pulmonary vascular resistance; RHC: Right heart catheterization; SD: Standard deviation \\ Acknowledgements \\ The authors give thanks to all ASD patients in Dr. Sardjito General hospital, who participated in this study. \\ Funding \\ This study used authors' personal funds. \\ Authors' contributions \\ $S, H D$, and AZA contributed to study conception and design; HD and AZA contributed to data acquisition, analysis, and interpretation; $S$ and HD contributed to article writing; S, HD, and AZA contributed to editing, reviewing, and final approving of article.}

\section{Ethics approval and consent to participate}

The study was reviewed and approved by the Faculty of Medicine, Public Health and Nursing, Universitas Gadjah Mada Institutional Review Board. The need of for individual informed consent was waived by Institutional Review Board of Faculty of Medicine, Public Health and Nursing, Universitas Gadjah Mada.

\section{Competing interests}

The authors declare that they have no competing interests.

\section{Publisher's Note}

Springer Nature remains neutral with regard to jurisdictional claims in published maps and institutional affiliations.

\section{Author details \\ ${ }^{1}$ Department of Thoracic and Cardiovascular Surgery, Dr. Sardjito General Hospital, Faculty of Medicine, Public Health and Nursing, Universitas Gadjah Mada, Kesehatan St. Number 1, Sleman, Yogyakarta 55281, Indonesia. \\ ${ }^{2}$ Faculty of Medicine, Universitas Islam Indonesia, Yogyakarta, Indonesia.}

Received: 3 October 2017 Accepted: 9 May 2018

Published online: 22 May 2018

\section{References}

1. Van Der Linde D, Konings EEM, Slager MA, Witsenburg M, Helbing WA, Takkenberg JJM, Roos-Hesselink JW. Birth prevalence of congenital heart disease worldwide: a systematic review and meta-analysis. J Am Coll Cardiol. 2011;58:2241-7 PMID: 22078432. https://doi.org/10.1016/j.jacc. 2011.08.025.

2. Kuijpers JM, Mulder BJM, Bouma BJ. Secundum atrial septal defect in adults: a practical review and recent developments. Neth Heart J. 2015;23:205-11 PMID: 25884091. https://doi.org/10.1007/s12471-015-0663-z.

3. Engelfriet $P$, Meijboom F, Boersma E, Tijssen J, Mulder B. Repaired and open atrial septal defect type II in adulthood: an epidemiological study of a large european cohort. Int J Cardiol. 2008;126:379-85 PMID: 17586067. https://doi.org/10.1016/j.ijcard.2007.04.044.

4. Badesch DB, Champion HC, Sanchez MAG, Hoeper MM, Loyd JE, Manes A, McGoon M, Naeije R, Olschewski H, Oudiz RJ, Torbicki A. Diagnosis and assessment of pulmonary arterial hypertension. J Am Coll Cardiol. 2009;54: s55-66 PMID: 19555859. https://doi.org/10.1016/j.jacc.2009.04.011.

5. Lowe BS, Therrien J, Ionescu-Ittu R, Pilote L, Martucci G, Marelli AJ. Diagnosis of pulmonary hypertension in the congenital heart disease adult 
population. J Am Coll Cardiol. 2011;58:538-46 PMID: 21777753. https://doi.org/10.1016/j.jacc.2011.03.033

6. Rodriguez FH 3rd, Moodie DS, Parekh DR, Franklin WJ, Morales DL, Zafar F, Graves DE, Friedman RA, Rossano JW. Outcomes of hospitalization in adults in the United States with atrial septal defect, ventricular septal defect, and atrioventricular septal defect. Am J Cardiol. 2011;108:290-3 PMID: 21545985. https://doi.org/10.1016/j.amjcard.2011.03.036.

7. Minai OA, Santacruz JF, Alster JM, Budev MM, McCarthy K. Impact of pulmonary hemodynamics on 6-min walk test in idiopathic pulmonary fibrosis. Respir Med. 2012;106:1613-21 PMID: 22902266. https://doi.org/10. 1016/j.rmed.2012.07.013

8. Miyamoto S, Nagaya N, Satoh T, Kyotani S, Sakamaki F, Fujita M, Nakanishi $\mathrm{N}$, Miyatake K. Clinical correlates and prognostic significance of six-minute walk test in patients with primary pulmonary hypertension. Am J Respir Crit Care Med. 2000;161:487-92 PMID: 10673190. https://doi.org/10.1164/ajrccm. 161.2.9906015

9. Lai YC, Potoka KC, Champion HC, Mora AL, Gladwin MT. Pulmonary arterial hypertension: the clinical syndrome. Circ Res. 2014;115:115-30 PMID: 24951762. https://doi.org/10.1161/CIRCRESAHA.115.301146.

10. Farouk A, Algowhary M, Hassan MH, et al. Circulating B-type natriuretic peptide levels and its correlation to Qp/Qs ratio among children undergoing congenital heart surgery. J Egypt Soc Cardio-Thoracic Surg. 2017;25(1):58-63. https://doi.org/10.1016/j.jescts.2017.03.002.

11. ATS Committee on Proficiency Standards for Clinical Pulmonary Function Laboratories. ATS statement: guidelines for the six-minute walk test. Am J Respir Crit Care Med. 2002;166:111-7 PMID: 12091180. https://doi.org/10. 1164/ajrccm.166.1.at1102.

12. de Assis Ramos R, Guimarães FS, Dionyssiotis Y, Tsekoura D, Papathanasiou J, de Sá Ferreira A. Development of a multivariate model of the six-minute walked distance to predict functional exercise capacity in hypertension. J Bodyw Mov Ther. 2018:1-7. https://doi.org/10.1016/j.jbmt.2018.01.010.

13. Omar HR, Guglin M. The longitudinal relationship between six-minute walk test and cardiopulmonary exercise testing, and association with symptoms in systolic heart failure: analysis from the ESCAPE trial. Eur J Intern Med. 2017:40:e26-8. https://doi.org/10.1016/j.ejim.2016.12.017.

14. Burr JF, Bredin SSD, Faktor MD, Warburton DER. The 6-minute walk test as a predictor of objectively measured aerobic fitness in healthy working-aged adults. Phys Sports Med. 2011;39(2):133-9. https://doi.org/10.3810/psm.2011. 05.1904

\section{Ready to submit your research? Choose BMC and benefit from}

- fast, convenient online submission

- thorough peer review by experienced researchers in your field

- rapid publication on acceptance

- support for research data, including large and complex data types

- gold Open Access which fosters wider collaboration and increased citations - maximum visibility for your research: over $100 \mathrm{M}$ website views per year

At BMC, research is always in progress.

Learn more biomedcentral.com/submissions 